\title{
Erratum to: The relationship between atmospheric lead emissions and aggressive crime: an ecological study
}

\author{
Mark Patrick Taylor ${ }^{1 *}$, Miriam K. Forbes ${ }^{2}$, Brian Opeskin ${ }^{3}$, Nick Parr ${ }^{4}$ and Bruce P. Lanphear ${ }^{5}$
}

\section{Erratum}

Subsequent to the publication of our article [1], we have now made the data available on figshare with the doi https://dx.doi.org/10.6084/m9.figshare.4109784.v1.

\footnotetext{
Author details

'Department of Environmental Sciences, Faculty of Science and Engineering, Macquarie University Energy and Environmental Contaminants Research Centre, Sydney, NSW, Australia. ${ }^{2}$ Centre for Emotional Health, Department of Psychology, Macquarie University, Sydney, NSW, Australia. ${ }^{3}$ Macquarie Law School, Faculty of Arts, Macquarie University, Sydney, NSW, Australia.

${ }^{4}$ Department of Marketing and Management, Faculty of Business and Economics, Macquarie University, Sydney, NSW, Australia. ${ }^{5}$ Department of Health Sciences, Simon Fraser University, Vancouver, BC, Canada.
}

Received: 25 November 2016 Accepted: 1 December 2016 Published online: 30 December 2016

\section{References}

1. Taylor MP, Forbes MK, Opeskin B, Parr N, Lanphear BP. The relationship between atmospheric lead emissions and aggressive crime: an ecological study. Environ Health. 2016;15:23. doi:10.1186/s12940-016-0122-3.

\footnotetext{
* Correspondence: mark.taylor@mq.edu.au

${ }^{1}$ Department of Environmental Sciences, Faculty of Science and Engineering, Macquarie University Energy and Environmental Contaminants Research Centre, Sydney, NSW, Australia

Full list of author information is available at the end of the article
} 